\title{
Ações de informação e práticas documentárias como políticas difusas de memória
}

\author{
Information actions and documentary practices as diffuse politics of memory
}

\author{
Geni Chaves Fernandes \\ Doutora em Ciência da Informação pelo IBICT/UFRJ. \\ Professora adjunta da Universidade Federal do Estado do Rio de Janeiro, UNIRIO. \\ E-mail: geni@centoin.com.br
}

\begin{abstract}
Resumo
Os estudos teórico-epistemológicos de González de Gómez e Frohmann, sobre as ações de informação e as práticas documentárias, permitem encontrar proximidades com as reflexões sobre os estudos da historiografia e da memória. Pode-se daí visualizar um dispositivo implicado na construção da memória, que chamamos de políticas difusas de memória. As reflexões dos historiadores e estudiosos da memória social acerca de suas responsabilidades com as narrativas do passado devem ser estendidas a outros atores, especialmente aos pesquisadores dos campos de estudos da informação e do documento.
\end{abstract}

Palavras-chave: ações de informação; práticas documentárias, memória documentária

\begin{abstract}
The theoretical-epistemological studies of González de Gómez and Frohmann on actions that constitute information and practices that produce documents allow finding neighborhoods with the reflections on history and memory studies. It allows visualizing a device involving the memory construction, that we call diffuse politics of memory. The reflections of the historians and researchers of the social memory concerning to their responsibilities with the narratives of the past ought to be extended to other actors, especially to the researchers of the fields of information and the document studies.
\end{abstract}

Key-words: information actions; documentary practices, documentary memory

\section{Introdução}

Os estudos de Maria Nélida González de Gómez das ações que constituem um valor de informação e os de Bernd Frohmann, que tratam das práticas sociais que constituem documentos e informações, são reflexões teórico-epistemológicas que servem de bases à compreensão dos processos informacionais, tendo especialmente em vista as propostas de políticas de informação. Seus quadros explicativos, entretanto, também se mostram relevantes para examinar tais ações e práticas a partir de aparatos institucionais, materiais e discursivo que aí se entrelaçam, em um dispositivo de memória, constituindo o que vamos denominar por políticas difusas de memória. Nosso interesse aqui é circunscrever tais políticas a partir de relações entre reflexões da historiografia e da memória e os quadros desenvolvidos por 
González de Gómez e Frohmann, o que parece nos convocar a ampliar o leque dos atores com responsabilidades éticas no âmbito das narrativas do passado.

Qualquer complemento ao termo "política de" remete à ideia de uma ação intencional sobre um aspecto da vida com vistas a alcançar uma configuração, um objetivo, um estado de coisas. A ideia de "política de" também remete ao entendimento de que existe um sujeito, individual ou coletivo, ou um comitê instituído, para planejar e levar a cabo tal política, portanto, uma noção de centralidade ou centro de onde partiriam tais ações.

Paul Ricoeur (2000, p. 97-110), tratando dos usos e abusos da memória, aponta a "memória convocada a lembrar" ou "obrigada a não esquecer", como resultante de políticas de memória desencadeadas no nível ético-político por grupos que, temendo o esquecimento de certos acontecimentos, agem de modo a manter suas lembranças vivas e atuantes no presente (holocausto, torturas); ou, ainda, o que chamou de "memória manipulada" ou "memória instrumentalizada", resultante de ações daqueles que querem impedir as recordações de certos acontecimentos por apagamento ou por colocação de um decalque (história de uma nação contada a partir de sua descoberta por outra nação; domingo, dia do Senhor e não de culto ao Sol). Tais ações, sejam usos ou abusos, articulam-se a políticas documentárias, quer dizer, critérios de validação documentária que, ao fim e ao cabo, influenciarão expressões autorizadas ou desautorizadas da memória. O que é ou não aceito como documento, como testemunha, deriva já de um conjunto de ações formativas e seletivas dispersas por variados atores e suas negociações, com interesses diversos.

No âmbito das políticas de informação, que influenciam na preservação documental, é interessante a pontuação feita por Frohmann (1995) ao examinar a literatura da CI (cf., também, GONZÁLEZ DE GÓMEZ, 1999b). Entendida, em geral, como uma ação exclusiva do governo ou do Estado, tal concepção de política de informação estaria, dentre outros aspectos, tirando de cena certos atores e os controles que exerceriam sobre os sistemas de informação, para além da ação governamental, configurando conformações da informação, em um regime de informação ${ }^{1}$.

\footnotetext{
${ }^{1}$ Frohmann (1995) entende por regime de informação a constituição de uma rede de atores (humanos e não humanos) que vai se articulando e estabilizando na medida em que negociam seus diversos, e por vezes antagônicos, interesses para gerar, capturar, organizar, fazer circular, vender, disseminar informações. Seu interesse está no exame do regime de informação contemporâneo, nos instrumentos e meios que dispõe para constituir a informação como um valor e seus efeitos. Para González de Gómez (1999a, 2003) o regime de informação seria o modo dominante de nossa formação social, de tal sorte que condicionaria os regimes sociais, econômicos, culturais, das comunidades e do estado. Embora não esteja explicitado pela autora, entendemos que
} 
Isto significa que o Estado, mesmo que colocasse ao seu encargo a condução de uma política de preservação de memória informacional/documentária, teria de lidar não com uma massa de informações e documentos sem direção, esperando que alguém lhe forneça um rumo, mas com uma rede articulada, de interesses diversos e negociados, que desenvolveu meios estabilizados e estabilizadores de produção, validação, captura, incorporação, circulação e comercialização de documentos e/ou informações. Daí, o exame de estoques e fluxos de documentos e informações, tenha em vista o desenvolvimento de instrumentos, tenha em vista uma meta de política de memória ou informação, que passasse ao largo do quadro já dado de forças constituintes e mantenedoras de documentos e de informações, teria sua eficácia comprometida.

É esta tarefa de mapeamento e consequente construção conceitual-teórica dos elementos e forças, cujas relações e ações constituem algo como sendo um valor de informação (ou como tendo valor informacional), que se colocam González de Gómez, ao tratar das "ações de informação", e Frohmann, ao tratar das "práticas documentárias". Seus alicerces teóricos encontram-se, especialmente, na teoria do ator-rede de Bruno Latour, Law e Callon e nos conceitos desenvolvidos por Michel Foucault em suas análises das práticas discursivas e não discursivas, especialmente na emergência dos conhecimentos sobre o homem (cf. FOUCAULT, 2005; 2007).

O que faz com que algo seja aceito "como sendo informação"? O que constitui algo como um valor de informação? É a indagação da qual partiu González de Gómez (1999a) para um percurso que indicou um conjunto de estratos ou camadas por onde algo deve passar para que se produza um valor de informação.

Buckland, ao analisar a proposta de Suzanne Briet acerca do que seja um documento, identifica que, dentre outros elementos, documento é aquilo que é "percebido como documento", o que considera uma posição fenomenológica; portanto, é preciso um acolhimento de algo "como" documento, em um horizonte (histórico-cultural) da compreensão. A indagação de Frohmann se coloca bem aí. Se documento é uma função que se ancora antes num reconhecimento/acolhimento, do que no exame de características neles constantes, de onde vem tal aceitação? Seu percurso é em direção do que denomina práticas documentárias institucionalizadas, que de certo modo são produtoras e validadoras de 
documentos (FROHMANN, 2004). Seu interesse também é indagar como algo, afinal, vem a ser aceito como informação. Sua resposta passa pelo documento e este pelas práticas documentárias.

É a partir de suas bases que tratamos aqui de fazer uma aproximação do que vamos chamar de "políticas difusas de memória" no âmbito da memória documentária, em suas relações com memória. Políticas porque são ações intencionais que põem ou retiram certos objetos da função de documento, colocam certas informações em evidência e tiram outras de evidência; difusas porque resultantes de uma diversidade de tensões e negociações de atores locais míopes. Nos termos de Latour, atores "[...] veem demasiado pouco para alimentar [alguma] megalomania [...] mas o que veem, veem bem [...] é possível obter visões sólidas, mas extremamente restritas do todo [...]”. (LATOUR, 2008, p. 260, tradução nossa).

\section{O Ciclo Documentário}

Amplamente utilizado na CI e na Biblioteconomia, especialmente como referência didática, o ciclo documentário será nosso ponto de partida. A proposta deste ciclo coloca-se, de início, como processamento ou tratamento de documentos e a recuperação de suas informações, no âmbito de uma Unidade de Informação (UI) - sejam arquivo, museu, biblioteca, centro de documentação -, subentendida em sua relação com o "exterior" como um sistema de informações colocadas ao dispor.

Num segundo momento, este "exterior" começa a influir no desenho de tal ciclo, aparecendo sob as formas de usuário (necessidades de informação) e fontes (produtores de conhecimentos registrados). Mas mesmo neste segundo momento pode-se pensar que as tarefas desenvolvidas neste ciclo são apenas técnicas para colocar informações ao dispor de usuários necessitados, acerca de conhecimentos registrados por aqueles que sabem. Pode-se mesmo pensar que, a bem de algumas interferências interpretativas pessoais (estrutura cognitiva) de seus profissionais, a UI opera uma organização neutra da informação e do conhecimento, tornando-os transparentes.

Os pressupostos que ancorariam tal suposição de neutralidade e transparência seriam, para González de Gómez (1999a, p. 11-12): (a) que o texto tem um significado fixo que pode ser expresso em um vocabulário privilegiado; (b) que a equivalência entre o documento primário e o secundário (resultante da análise documentária) pode ser garantida por 
regularidades linguísticas ou semânticas; (c) e que é possível estabelecer técnicas de leitura documentária que minimizem diferenciais subjetivos na interpretação. Esse modelo de ciclo documental opera, portanto, pela

[...] redução ao plano polimórfico das ações de informação e pela sobredimensionalização dos planos mais estáticos e sujeitos a regularidades previsíveis como o plano morfológico e sintático da linguagem e do software, nos sistemas de tratamento de textos. (GONZÁLEZ DE GÓMEZ, 1999a, p. 12).

Mas os incômodos e insatisfações de entendimento do documento e da informação levaram a um novo momento, fazendo as pesquisas em CI avançarem para este "exterior", no exame mais detalhado dos usuários e usos da informação, da comunicação científica e organizacional, do papel que exercem caminhos já consagrados de pesquisa em áreas de conhecimento, de interesses políticos e econômicos, de editoras, editores, de novas tecnologias, etc.

Se adotarmos as propostas teóricas de González de Gómez e de Frohmann, que é o nosso caso, já não é mais possível o entendimento do ciclo documentário restrito ao âmbito das UIs, nem supor as relações constituintes de documentos e de informações em locais determinados, que podem ser entendidos isoladamente em um exame. Não há, por assim dizer, um "interior" e um "exterior". Não se trata aqui de abandonar o ciclo que se dá dentro das UIs; trata-se, antes, de dar conta de sua inserção em um processo produtivo mais amplo de documentos e informações, do qual a UI faz parte.

Podemos pensar no circuito que um documento percorre antes que chegue a uma UI? O rastreamento do percurso deste móvel, nos termos de Latour, permitiria ver ao menos parte das diversas intervenções "[...] provenientes de algum outro momento, algum outro lugar e gerados por alguma outra agência" (LATOUR, 2008, p. 238, grifo do autor). O exame que se detivesse nessas intervenções possivelmente levaria a um conjunto de negociações com diversos interesses constituídos no passado que estabilizam normas, regras e padrões, cujas justificativas aparecem no lugar destes interesses negociados. Tomemos um caso hipotético de percurso de um artigo científico, publicado em um periódico, para identificar as intervenções oriundas de "outros momentos", de "outros lugares" e de "outras agências".

O último número de um periódico eletrônico de química, que acaba de ser adquirido por uma biblioteca, traz um artigo sobre componentes para produção de um defensivo agrícola contra pragas que costumam afetar a produção de soja. A química é uma ciência reconhecida e não conseguiu tal posição da noite para o dia e muito menos sem seguir 
normas, fundamentos e critérios conhecidos e praticados por nosso autor. $\mathrm{O}$ autor do artigo ingressou em uma instituição de pesquisa em química e, embora seu desejo inicial fosse desenvolver conhecimentos para produção de novos materiais para construção, acabou engajando-se na linha de pesquisa ali existente, compostos químicos para agricultura.

Elaborou um projeto de pesquisa, seguindo o edital de uma agência governamental de fomento concorrendo com diversos competidores. O desenvolvimento da Ciência e Tecnologia (C\&T) foi sistematicamente fomentado com o capitalismo e, depois da segunda guerra mundial, o Estado do Bem-Estar assumiu esta tarefa, estruturando instâncias de avaliação e de fomento. A agência de fomento, que pauta seus critérios de seleção de projetos para financiamento: pela quantidade de recursos que dispõe, pela mensuração da produtividade dos pesquisadores (que é minuciosamente controlada por outra agência) e pelas diretrizes estabelecidas pelo governo em exercício, - exportar soja para aumentar as divisas estrangeiras, sob pena de queda de aprovação do governo, encontra-se entre elas -, concedeulhe o financiamento.

Sua pesquisa seguiu todos os critérios e passos exigidos para que os resultados fossem considerados válidos, incluindo número de testes, dados de precisão, equipamento e condições adequadas aos experimentos. Os resultados foram colocados em um relatório apresentado à agência de fomento e à instituição de pesquisa na qual trabalha. Nosso autor foi instado a submeter o composto químico ao registro de patente, afinal, o resultado era vendável e a patente vista como um meio para obter novos recursos para pesquisa, melhorando possivelmente a posição da instituição no ranking deste campo. $\mathrm{O}$ assunto era controvertido entre os pesquisadores, havendo muitas resistências. A maioria entendia que publicar os resultados obtidos é uma espécie de desejo imperativo de qualquer pesquisador. A publicação de uma carta patente - negociável - garante ao proprietário a exclusividade de produção por um período determinado, mas a publicação sob a forma de artigo fornece reputação ao autor em seu meio, e é um modo de garantir a prioridade de sua descoberta, quer dizer, faz do artigo publicado uma prova (cf. MEYRAT, 2006, p. 17, sobre o artigo como prova ou comprovante). Resolveu publicar o artigo. Entrou no sítio da revista escolhida, que é eletrônica (ele tem o necessário computador e acesso à rede). Os periódicos eletrônicos, hoje tão comuns, sofreram resistências e desconfianças iniciais quanto a sua qualidade, limitações de acesso, riscos de perda, mudança de formato, acesso aos números impressos. Mas, 
especialmente seus baixos custos concorreram para sua ampla aceitação ${ }^{2}$. No sítio da revista nosso autor buscou os critérios para conformar a redação de seu artigo: felizmente ele já utilizava o Word na versão requerida, mas teve que suprimir vários elementos do relatório para que o artigo ficasse com o máximo de 15 páginas, espaçamento entrelinhas de 1,5, Times New Roman, tamanho da fonte 12 etc., etc.

Recebeu parecer que requeria uma revisão da redação segundo as novas normas ortográficas acordadas entre os países de língua portuguesa e que suas citações e referências seguissem as normas da ABNT. O acordo dos países de língua portuguesa nada tem a ver com química. Sustenta que a existência de duas ortografias é prejudicial para unidade do português e para o prestígio de nossa língua no mundo. Embora haja argumentos de que as diferentes ortografias não impediriam as vendas de autores brasileiros em Portugal e de autores portugueses no Brasil, veja-se o sucesso de Saramago, a reedição de livros, de dicionários, de gramáticas, impressos e eletrônicos, dentre outros, é muito bem vista e defendida pelas editoras.

Voltemos a nosso autor que, depois de lutar contra seu velho corretor automático de textos do Word, que insistia em corrigir erroneamente a grafia agora certa, ajustou seu texto conforme o acordo. Quanto às citações e referências, nosso autor jamais havia lido tais normas e sempre havia imitado o modo de apresentação que via em outros trabalhos, mas tratou de adquirir e de seguir as normas, muito embora elas não tivessem nada a ver com seu trabalho sobre defensivos agrícolas. A ABNT, por seu turno, não tem qualquer interesse especial em defensivos, mas nos acordos internacionais que estabelecem normas técnicas que permitem que padrões, como é o caso do tamanho e formato de plugs e tomadas, façam com que qualquer aparelho se encaixe em qualquer tomada. As normas e padrões técnicos estabeleceram-se amplamente após a Revolução Industrial, que proporcionou o aumento da produção industrial e a intensificação do comércio (com as máquinas trens e navios a vapor) e, especialmente, após a adoção do modo de produção chamado fordista, de linha de montagem, onde peças produzidas por diferentes fabricantes devem se encaixar perfeitamente.

\footnotetext{
2 Conforme explica Paula Neto (2005, p. 27), os consórcios de bibliotecas (bibliotecas em rede ou compartilhantes de recursos) necessitam de licença para o uso de publicações eletrônicas, que requer negociações de contratos com cada editor, bem como o conhecimento legal desta modalidade de acesso e uso, além de tecnologias de informação adequadas. Portanto, o início de tal processo não podia dar-se sem resistências, custos, negociações e nem da noite para o dia.
}

InCID: R. Ci. Inf. e Doc., Ribeirão Preto, v. 2, n. 1, p. 208-226, jan./jun. 2011. 
Finalmente, o artigo sobre o assunto de pesquisa que nosso autor partilha com seus pares, aceito no campo da química, cujos experimentos e resultados seguiram os fundamentos e as normas metodológicas de pesquisa de seu campo, no formato eletrônico da revista, no tamanho máximo aceito, dentro das normas da língua portuguesa e da ABNT, foi publicado e chegou à UI, sob forma de acesso eletrônico.

O periódico eletrônico, considerado de interesse e dentro dos limites orçamentários da UI entrou no processamento técnico. O processamento gerará, com este e outros documentos, artefatos de informação (PACHECO, 1995). É claro que, num contexto de escassez, e sempre estamos em contextos de escassez, outros periódicos terão que ficar de fora (não são do assunto que interessa à maioria dos usuários, não têm um bom qualis, são muito caros) e, portanto, também ficarão de fora artigos publicados em revistas não adquiridas, assim como os que ficaram no meio do caminho da publicação, porque os projetos não foram financiados, o texto não entrou nos formatos requeridos, as pesquisas sobre o assunto não são consideradas relevantes pelos pares, não seguiram as normas de validação dos experimentos, e por aí vai.

Podemos dizer que os artigos e demais inscrições que entram em uma UI já são considerados ou reconhecidos como documentos (ajustados, normalizados, adequados, selecionados, validados) e serão organizados e disponibilizados segundos certos critérios, em artefatos informacionais: catálogos, bibliografias, resumos, palavras-chave etc., em vista do resgate e reintrodução do que já foi publicado em possíveis novas publicações. Por isso González de Gómez afirma que "[...] a ação de documentar antecipa e condiciona o que será produzido e reconhecido como documento.” (GONZÁLEZ DE GÓMEZ, 1999a, p. 9).

Neste circuito não há um "exterior" ou um "interior", mas atores que concorrem, no duplo sentido do termo, e interferem no circuito de produção de um documento e de um valor de informação com interesse os mais diversos.

Outros circuitos se aplicam à produção de documentos como é o caso de um filme ou de um catálogo de uma filmoteca, a uma matéria publicada em um jornal (cf. SOUZA, 2007), de um memorando e do arquivo da empresa que o classificará e manterá. Cada ator, cujas práticas seguem critérios institucionalizados e instrumentos aceitos, atua neste circuito como construtor, validador, conformador dos documentos e informações que produzem, assim como são conformados, neste processo produtivo, em documentadores e informantes, ao menos assim pensa Bernd Frohmann. Documentar, enquanto uma prática produtora de documentos, exige um praticar, e tais práticas são socialmente disciplinadas (FROHMANN, 2004).

InCID: R. Ci. Inf. e Doc., Ribeirão Preto, v. 2, n. 1, p. 208-226, jan./jun. 2011. 
Frohmann apropria-se da concepção foucaultiana que toma certas práticas sociais (práticas de subjetivação e objetivação) como constituintes dos sujeitos, tanto dos sujeitos que ocupam lugares de autoridade de saberes como dos sujeitos tornados objeto destes saberes, para aplicá-las ao entendimento do documento: sua sustentação, sua autoridade, seus efeitos, e exemplifica com dois casos.

O primeiro (FROHMANN, 2004) é o da passagem da ciência da observação para a ciência do experimento, tratando-se da constituição de práticas documentárias. Se uma observação da natureza podia ser confirmada por qualquer um, em qualquer lugar, como garantir tal aceitabilidade quando a ciência passa para o âmbito do experimento, que só pode ser reproduzido dentro de condições artificiais específicas? Foi necessária a construção de uma estrutura argumentativa padronizada, normas de descrição, apresentação de axiomas etc. Enfim, um conjunto de procedimentos que tanto buscavam dar confiabilidade aos resultados observados no experimento, padronizá-los par uma diversidade de locais/tempos, assim como exigia do cientista sua conformação a este modo de documentar.

O outro caso (FROHMANN, 2008) apresentado é de um pesquisador na Costa do Marfim, que obteve recursos de indústrias farmacêuticas para desenvolver pesquisas sobre AIDS. Os doentes, convertidos em pacientes (aceitando proceder do modo prescrito pelo médico pesquisador) transformam-se em testemunhas confiáveis para produção de informações, que foram documentadas segundo a prática médica. Assim, numa aliança de diferentes interesses: do médico que queria pesquisar sobre AIDS, dos doentes, que recebiam tratamento e remédios gratuitamente, dos laboratórios que forneciam recursos em troca de informações sobre a pesquisa, desde que produzidas segundo as normas cientificamente autorizadas, explicitam disciplinas sociais requeridas para a aceitação de um documento ou de informação.

É no exame das práticas "[...] a que deve submeter-se o sujeito, que estatuto deve ter, que posição deve ocupar para poder se sujeito legítimo do conhecimento" e a que condições deve submeter-se para tornar-se objeto do conhecimento (de doente a paciente) (CASTRO, 2009, p. 408), ou, nos nossos termos, para tornar-se uma testemunha, que se constituem documentos. Seus caracteres de autoridade e de evidência decorrem de tais práticas. Podemos dizer que nosso autor está submetido a tais práticas que o "produzem" enquanto documentador e que condicionam o que será ou não reconhecido como documento. 
A ordenação proporcionada e os conflitos e tensões que aparecem em nosso exemplo procuram indicar que práticas documentárias estão sempre sujeitas a forças e jogos de interesses diversos e locais, que acabam por estabelecer uma ampla rede. O circuito pelo qual passa o artigo de nosso autor é ordenador, ali “[...] os efeitos de poder são geridos de forma relacional e distribuída [...]", e as resistências demandam constantes processos de negociação (tradução, na teoria do ator-rede) para equivaler interesses (LAW, 200-?, p.7). O circuito precede, e nele estão os elementos que condicionam, o ciclo documental que, por sua vez, geram novos produtos (artefatos informacionais) altamente seletivos e direcionados, que interferirão no circuito de produção de novos documentos.

\section{As Ações de Informação e as Práticas Documentárias}

A concepção deste circuito, a partir do exame de seus estratos e sub-estratos, foi realizada por González de Gómez (1999a; 2000) e Frohmann (1994), baseados no modelo de Collins (1981, 1983, citado por FROHMANN, 1994). São identificados três estratos como estágios na construção da informação. Vamos tratar de apresentá-los e, ao mesmo tempo, fazer algumas reflexões e adjunções.

(i) O estrato Informacional ou Semântico é aquele onde o que está sendo proposto encontra-se em um ambiente de flexibilidade interpretativa. É um ambiente de práticas, onde se encontram debates, divergências, disputas, sejam para a produção de um novo modelo de sapato, de uma tecnologia, de um conceito teórico, portanto, também de produção de saberes. É claro que, em qualquer ambiente produtivo já existem parâmetros pré-estabelecidos que norteiam o alcance desta flexibilidade.

Mas o que comanda, em uma esfera de produção, o direcionar de energias para produzir algo novo? Quer dizer, o que é que dirige, aponta ou estimula a produção de um conceito ou teoria, de um novo modelo de sapato, ou de uma tecnologia? Certamente muitos podem ser os fatores intervenientes, especialmente os discursos imperativos da concorrência, da produtividade, da inovação, mas a busca e apropriação da informação colocam-se hoje como indispensáveis. São informações sobre o mercado, sobre os concorrentes, sobre novos conceitos, sobre desejos de consumidores, sobre a nova moda, que de certo modo condicionam a produção. Como entende González de Gómez (2003, p. 61), contemporaneamente o regime de informação, enquanto modo de produção informacional,

InCID: R. Ci. Inf. e Doc., Ribeirão Preto, v. 2, n. 1, p. 208-226, jan./jun. 2011. 
“[...] caracteriza e condiciona todos os outros regimes sociais, econômicos, culturais, das comunidades e do Estado."

Aí se entrelaçam, nas práticas produtivas, os saberes locais e a busca por informações disponibilizadas por artefatos produzidos pelas UIs. Portanto, este extrato de flexibilidade interpretativa, que origina diferentes respostas acerca do que diz o mercado, o texto, os consumidores, já conta com parâmetros. Daí, “[...] o 'informar' e o 'buscar informação' antecipam e condicionam a concepção ou aceitação de algo como informação [...]" (GONZÁLEZ DE GÓMEZ, 1999a, p. 9, grifo da autora).

Não é por acaso que métodos de estimulação de troca e de captura de informação ou conhecimentos sejam objeto de destaque nas abordagens sobre inovação tecnológica não só na CI, mas especialmente na economia, administração de empresas, engenharias. São as informações, talvez mais do que a imaginação ou criatividade, o que se considera como base para processos inovativos.

Nesse estrato aplicam-se critérios de validação e aceitação de algo como informação nas redes prático-discursivas (GONZÁLEZ DE GÓMEZ, 1999a, p. 20 e 25). Estes critérios incidem em dois hemisférios articulados:

- Aplicam-se ao que é possível dizer e fazer, ou seja, a flexibilidade encontra limites tanto no campo discursivo (na psicologia não há possibilidade de abordar um fenômeno como parapsicológico) como nas práticas, onde regras e critérios para argumentação precisarão ser obedecidos.

- Aplicam-se, também, ao que é acolhido como informação, quer dizer, as informações utilizadas para sustentar as diferentes argumentações neste estrato são as que podem ser encontradas (a partir de artefatos de informação) porque foram validadas no processo de construção documentária. São estas que poderão ser reintroduzidas no processo de produção de um novo conceito, modelo de sapato, tecnologia etc. É sobre o reconhecido (estabilizado) que aparecem os conflitos, os argumentos, as discussões, as evidências (GUYOT; PEYRELONG, 2006, p. 53).

ii) $\mathrm{O}$ estrato metainformacional, ou infra-estrutural, é aquele “[...] onde se estabelecem as regras de sua interpretação e distribuição, especificando o contexto onde uma informação tem sentido" (GONZÁLEZ DE GÓMEZ, 1999a, p. 9; 2000). São regras e regulamentações constituídas por diversas instâncias (no nosso exemplo: a ciência, a 
especialidade, os pares, a ABNT, a gramática oficial etc.), ou de práticas documentárias, na expressão de Frohmann, cujas ações constituem mecanismos de conformação e controle.

Para ser aceito hoje como documento do tipo livro pontuado no mundo acadêmico, por exemplo, é necessário o ISBN. O ISBN identifica o livro, sobre o qual se constituíram direitos; a editora poderá fazer, e geralmente faz, com que o autor abra mão de todo o parte de seus direitos, mas manterá o copyright por muitos anos (DARNTON, 2010, p. 25). O autor, que não é editor e nem conta com canais de distribuição, irá se submeter a uma delas sob pena de não ter contabilizada sua produção pela instituição de avaliação, o que implicaria na redução de seu prestígio e dificuldades para ter acesso a novos financiamentos para suas pesquisas.

Mas a restrição da aceitação também poderá ser oriunda de elementos materiais ou tecnológicos. Por exemplo, se a aceitabilidade de registro de certo tipo de experimento depende de sua mensuração com precisão, que é aceita se realizada com determinado instrumento eletrônico, os resultados obtidos pelos experimentos que não utilizem tal instrumento não serão aceitos. Portanto, apresentam-se aí “[...] estratos materiais e tecnológicos que configuram ou intervém nos sistemas sociais de inscrição de significados [...]" (GONZÁLEZ DE GÓMEZ, 1999a, p. 8).

Se no estrato anterior o limite à flexibilidade era algo de certo modo internalizado pelos participantes, no estrato metainformacional haveria um fechamento de tal flexibilidade por limites oriundos da relação com diversas instâncias intervenientes na produção documental (FROHMANN, 1994). Aqui se conformam os documentos, e os assuntos tratados nestes documentos. Para Meyriat (2006) este processo de produção, configurador e validador dos documentos, é também o processo de perda de informatividade, seja pelo tempo necessário à produção e divulgação (diversos sub-estratos de conformação e validação), seja por cortes e sanções de natureza material ou intelectual, seja por barreiras que no momento se coloquem como instransponíveis etc.

(iii) E a constituição de artefatos informacionais, no sentido de um produto material, ou dos dispositivos de informação, nesse caso quando olhamos o conjunto preexistente de documentos reunidos numa "[...] memória de ações de informação [...] junto com os instrumentos e meios disponibilizados pelo ambiente cultural" (GONZÁLEZ DE GÓMEZ, 1999a, p. 9). Os termos utilizados por González de Gómez para referir-se aos efeitos do dispositivo são "matéria informada", "mediação maquínica", "passado instituído no mundo 
social", trata-se, portanto, do estrato onde se reúnem documentos, numa memória documental e constroem-se instrumentos e meios para sua relação e disponibilização através de artefatos informacionais. Deste modo, a biblioteca de economia em um instituto de pesquisas, os setores de pessoal e de contabilidade de uma indústria, um arquivo público ou privado, ou o IBGE, são sistemas de informação e pontos visíveis de dispositivos produtores de artefatos de informação, segundo certos critérios (de seleção, de formato, de tecnologia etc.), que instituem acervos documentários sobre o passado no mundo social. Se os observamos enquanto sistemas de informação, cada qual é "[...] tecnicamente disponibilizado: inserido na ação; contextualizado e institucionalizado, propositalmente desenvolvido e sempre em desenvolvimento (sujeito a mudanças). (GONZÁLEZ DE GÓMEZ, 2004, p.58). “Nesse sentido, um sistema seria a expressão de uma vontade e de um projeto organizacional; o dispositivo aponta a efeitos e resultados" (GONZÁLEZ DE GÓMEZ, 1999a, p. 23-24). O dispositivo coloca ao dispor certos documentos e informações para reutilização no processo produtivo, num circuito de agentes que abarca e condiciona o sistema. Segundo González de Gómez (2004), sobre o dispositivo os agentes formulam suas estratégias, sejam de preservação, sejam de modificação. Uma estratégia de mudança com sucesso implicará na interferência sobre todo o circuito.

Este estrato é, portanto, fortemente condicionado pelo estrato metainformacional, já que as negociações e estabilizações do que é ou não é aceito como documento em geral ou em uma área ou atividade específica, já condiciona sua captura para ingresso em mecanismos de tratamento e disponibilização de informações. Os aspectos ou assuntos tratados, sua pertinência, sua atualidade, dentre outros, serão norteadores da construção dos instrumentos para tratamento e recuperação, combinados com o mapeamento das demandas no âmbito dos usos no estrato informacional, onde os artefatos de informação fornecerão os meios para acessar e reutilizar o que está disponível. Portanto, temos um circuito articulado de estratos com sub-estratos que

[...] agem no modo de uma "cascata", de modo que o que se faz em um estrato bem ou de modo inadequado - afetará o próximo, que afetará o seguinte, e assim sucessivamente, alcançando todos os estratos. (GONZÁLEZ DE GÓMEZ, 2003, p. 61).

Há um entrecruzamento de práticas documentárias e ações de informação, herdadas, e mantidas sempre em negociações, por uma diversidade de agenciamentos, que, ao fim e ao cabo, fazem com que reconheçamos algo como documento ou como informação. Isto nos indica um único circuito de produção e de reprodução das "realidades" documentais e 
informacionais. Uma vez que tais "realidades" são aceitas, sejam como provas, comprovantes, evidências, aquilo que transforma estruturas, unidades de conhecimento, produção de sentido, ou outras definições que possamos para elas encontrar, podem-se examinar as práticas documentárias e as ações de informação enquanto políticas difusas e seus efeitos na construção da memória.

\section{Políticas Difusas De Memória}

O termo política de memória implica em dois âmbitos articulados de ações no agora: um em vista de manter memória de acontecimentos presentes e os meios para uma dada interpretação destes acontecimentos no futuro; o outro de ações que lembram e evidenciam, ou excluem e encobrem, acontecimentos e interpretações do passado. Objetos, inscrições, lembranças e esquecimentos entram na tecedura do passado, numa trama urdida no presente. Por exemplo, a trama que urdiu uma trajetória evolutiva para a Humanidade e a Razão no século 19 sustentava-se numa narrativa histórica que fez declinar o valor da memória documentária como fonte da sabedoria do passado em favor de uma memória documentária que servia de evidência da superioridade do presente sobre o passado (BENNETT, 1996, p.156; RICOEUR, 1997, p. 198).

Se os estudos da memória como construção social sobre o vivido de Maurice Halbwachs, em meados do século 20, tiveram um caminho paralelo e mesmo de oposição à história, a memória social ganhou espaço na historiografia a partir dos anos 1990 (SILVA, 2002). A luta para manter vivas recordações de eventos violentos (campos de concentração, torturas e opressões coloniais) e a guinada que Searlo (2007, p. 30) diz que poderia se chamar, frente à "morte do sujeito" do estruturalismo, de o "sujeito ressuscitado", foram estímulos à retomada e robustecimento deste debate teórico e político, que caminharia junto com a historiografia. Os obstáculos que se colocaram interna e externamente à historiografia às pretensões positivistas (MARX; ENGELS, 2006; NIETZSCHE, 1976), evolucionistas ou totalizantes da história (HALBWACHS, 1950; FOUCAULT, 2005), assim como importantes reflexões sobre o fazer do historiador $(\mathrm{BLOCH}, 19--$ ?; CERTEAU, 2007), implicaram na complacência do conceito de documento histórico. Não se abriu apenas o leque das "evidências" por incorporação de documentos antes fora da categoria, mas efetivou-se a mudança do que era evidente como sendo histórico. Quando as abordagens históricas passam a se ocupar " [...] com o mundo da experiência comum (mais do que a sociedade por si só) 
como seu ponto de partida [...]" (BURKE, 1992, p. 23), colocam à vista experiências antes consideradas irrelevantes para a história. Vale tanto para os documentos como para a história a afirmação que nada é evidente por si mesmo, antes, só é evidência o que está colocado em evidência (WILSON, 1995 citado por BUCKLAND, 1997). Assim, fazer falar setores da história e incorporar como documentos objetos antes ignorados é fazer "[...] uma redistribuição do espaço [histórico] e consiste, primordialmente, em se dar um lugar [...]" (CERTEAU, 2007, p. 83). O que é ou não é histórico implica, posto isto, em incluir, retirar, ou remanejar algo da narrativa histórica.

Certeau situa a historiografia, do ponto de vista de sua inserção social, em relação com seu não-dito, relação com as instituições, meios, tradições, imposições e constrangimentos inescapáveis que não invalidam suas pesquisas, como se fosse uma "inconfessável intromissão", antes como relações que "[...] constituem a textura dos procedimentos científicos.

\footnotetext{
Cada vez mais o trabalho se articula com base em equipes, líderes, meios financeiros e, portanto, também pela mediação de créditos, fundamentados nos privilégios que proximidades sociais ou políticas proporcionam a tal ou qual estudo. É, igualmente, organizado por uma profissão que tem suas próprias hierarquias, suas normas centralizadoras, seu tipo de recrutamento psicossocial. (CERTEAU, 2007, p. 73, grifo do autor).
}

Na relação, nem sempre pacífica, entre história e memória, a memória é a principal matriz, mutável e translúcida, da história, e esta, a narrativa do passado, construída a partir da memória, de hipóteses teóricas, metodologias e evidências documentais (memória, inscrições, objetos).

O historiador tem compromissos com o presente, onde se criam as condições para sua pesquisa, pois é no presente que se obtêm recursos, se demandam revisões interpretativas de narrativas do passado, é no presente que grupos lutam para que se dê lugar a passados esquecidos, enfim, é o presente que pode requerer um passado que lhe forneça sentido. Mas o historiador tem também compromissos com o passado, se não mais para fornecer seu retrato verdadeiro, ainda the guarda "fidelidade", de forma a que não se o torçam em função de enganos, de desejos de apagamento ou de vingança. Daí que mesmo com aproximações da memória, a história ainda se coloca com funções pedagógicas e corretoras em relação àquela, seja pelo compromisso com o passado, mesmo considerando sua tarefa interpretativa, seja pelos conflitos que a historiografia enfrenta com demandas de maior fidelidade ao passado, 
requeridas por relatos de acontecimentos vividos (relatos de memória) que ganharam vigor comercial (SEARLO, 2007; RICOEUR, 2000, p. 66).

Para Le Goff, a memória é mítica e deformada e é “[...] desejável que a informação histórica, fornecida pelos historiadores de ofício, vulgarizada pela escola [...] e pelo mass media, corrija esta história tradicional falseada. A história deve esclarecer a memória e ajudála a retificar os seus erros." (LE GOFF, 1996, p. 29). O mesmo pensa Burke, para quem a memória é fonte para história, mas deve ser examinada pelo historiador permitindo "[...] uma crítica da fiabilidade da reminiscência, na linha da crítica tradicional de documentos históricos.” (BURKE, 1992, p. 236).

A autoridade da história, a bem de possíveis resistências da memória, e suas alianças estáveis ou eventuais com outros saberes que se desdobram em certos lugares - Museu, Arquivos, Bibliotecas, escolas e mídias de massa - são canais por onde a narrativa histórica encontra meios de colonização de sua matriz, a memória. Não se trata aí necessariamente de uma dominação, mas de um povoamento da memória pela história, ora fácil, quando se encontram espaços disponíveis, ora difícil, quando há conflitos de vizinhança, ora impossíveis, quando a memória ri da narrativa histórica e não abre mão de suas recordações. É nesse jogo entre matriz e colonizador que memória e história se fazem e refazem.

Mas, se não há história sem memória, também não há história sem arquivo/documento. Se a existência de arquivos depende sempre de uma manutenção presente, porque só existe arquivo no presente, o que é ou não aceito como documento histórico ou digno de preservação (memorável) passou por um circuito que precedeu a narrativa histórica. Para haver arquivo hoje foi necessário um ato primeiro de seleção e de arquivamento e um segundo ato, contínuo, que deve manter sempre presente o arquivo (SILVA; FERNANDES, 2009). Conforme Certeau (2007, p. 81), quando a tarefa da história começa, ela já tem de lidar com os arquivos constituídos por uma combinação de grupos capazes e potentes para selecionar e manter documentos, de lugares como o Arquivo e a Biblioteca e de práticas e técnicas de impressão, de cópia, de comunicação etc.

Se as reflexões da historiografia e da memória social apontam, nas narrativas sobre o passado, uma responsabilidade que pesa sobre os historiadores e estudiosos da memória social, as propostas de González de Gómez e Frohmann propõem uma ampliação dos que devem assumir tais responsabilidades. As práticas documentárias e as ações de informação fazem aparecer documentos e artefatos informacionais não como apenas recursos para 
consulta e uso, que permitem desvendar o passado ou produzir algo no presente, mas como "realidades" resultantes da tensão constituinte do passado e do presente, da memória e da narrativa histórica. $\mathrm{O}$ circuito de produção dinâmico que enlaça a produção de documentos e de artefatos informacionais pode ser visto, pois, como um dispositivo que constitui, no presente, uma política difusa de memória.

González de Gómez e Frohmann nos colocam diante de uma complexidade de entrecruzamentos que não somos capazes de percorrer plenamente, apenas esboçar um mapa reduzido. Mais do que preservação da memória em documentos, defrontamo-nos com modos de colonização da memória, por meio de documentos, uma memória que não pode ser desembaraçada dos documentos e dos muitos interesses, meios, instituições que os constituem. Para além da perplexidade imediata que trazem, estes estudos aparecem já como uma dobra, uma reflexão e, consequentemente um modo de intervenção. Convocam os campos de estudos do documento e da informação ao mapeamento e análise, em esferas diversas, das interveniências - étnicas, políticas, econômicas, culturais -, e seus interesses, na tecedura presente do passado e do presente para o futuro, que perpassam a constituição de realidades documentais e informacionais, abrindo as possibilidades de oposições e intervenções intencionais.

\section{Referências}

BENNETT, T. The birth of the museum: history, theory, politics. London, New York: Routledge, 1996.

BLOCH, M. Introdução à história. 6. ed. Tradução de M. Manuel e R. Grácio. [Lisboa]: Europa-América, [19--?].

BUCKLAND, M. K. What is a "document'? JASIS, v. 48, n. 9, p. 804-809, Sept. 1997.

Disponível em: <http://people.ischool.berkeley.edu/ buckland/whatdoc.html>. Acesso em: 22 ago. 2006.

BURKE, P. A história como memória social. In: O mundo como teatro: estudos de antropologia histórica. São Paulo: Difel, 1992. p. 235-251.

CASTRO, E. Vocabulário de Foucault. São Paulo: Autêntica, 2009.

CERTEAU, M de. A escrita da história. 2. ed. Rio de Janeiro: Forense Universitária, 2007.

DARNTON, R. A questão dos livros: passado, presente e futuro. São Paulo: Cia. das Letras, 2010. 
FOUCAULT, M. A arqueologia do saber. 4. ed. Rio de Janeiro: Forense Universitária, 2005.

As palavras e as coisas: uma arqueologia das ciências humanas. 9. ed. São Paulo: Martins Fontes, 2007. (Coleção Tópicos).

FROHMANN, B. The social and discursive construction of new information technologies. In: INTERNATIONALES SYMPOSIUM FÜR INFORMATIONSWISSENSCHAFT, 4., 1994, Graz. Proceedings... Graz: Universitätserlang Konstanz, 1994. Disponível em: $<$ http://citeseerx.ist.psu.edu/viewdoc/download?doi=10.1.1.134.3443\&rep=rep1\&type=pdf $>$. Acesso em: 22 maio 2009.

Taking information policy beyond information science: applying the actor networ theory. In: ANNUAL CONFERENCE OF CANADIAN ASSOCIATION FOR INFORMATION, 23., 1995, Alberta. Proceedings ... Alberta: Hope A. Olson \& D.B. Ward, 1995. Disponível em: <http://www.cais-acsi.ca/proceedings/1995/frohmann_1995.pdf>. Acesso em: 22 maio 2006.

Documentation redux: prolegomenon to (another) phylosophy of information. Library Trends, v. 52, n. 3, p. 387-407, Winter 2004. Disponível em: $<$ http://www.ideals.illinois.edu/bitstream/handle/2142/1683/frohmann387407.pdf?sequence= 2>. Acesso em: 26 nov. 2009.

Documentary ethics, ontology, and politics. Archival Science, v. 8, n. 3, p. 165-180, Sept, 2008. Disponível em: <http://www.springerlink.com/content/9427530432303758/>. Acesso em: 23 mar. 2010.

GONZÁLEZ DE GÓMEZ, M. N.. O caráter seletivo das ações de informação. Informare, Rio de Janeiro, v. 5, n. 2, p. 7-30, jul./dez. 1999a.

Política e gestão da informação: novos rumos. Ciência da Informação, Brasília, v. 28, n. 2, maio/ago. 1999b. Disponível em: <http://revista.ibict.br/index.php/ciinf/article/view/274/242> . Acesso em: 10 jul. 2007.

. Metodologia de pesquisa no campo da Ciência da Informação. DataGramaZero, v.1, n. 6, dez. 2000. Disponível em: <www.dgz.org.br/dez00/Art_03.htm>. Acesso em: 12 nov. 2004.

.As relações entre ciência, Estado e sociedade: um domínio de visibilidade para as questões da informação. Ciência da Informação, Brasília, v. 32, n. 1, p. 60-76, jan./abr. 2003. Disponível em: < http://revista.ibict.br/index.php/ciinf/article/view/131/112>. Acesso em: 22 mar. 2004.

Novas fronteiras tecnológicas das ações de informação: questões e abordagens. Ciência da Informação, Brasília, v.33, n. 1, p. 55-67, jan./abr. 2004.

GUYOT, B.; PEYRELONG, M-F. Le document dans une perspectrive organizacionnelle: um objet comme um autre? In: COURBIÈRE, C.; RÉGIMBEAU, G. Dimensionn sociales du document. Toulouse: Press Universitaire du Mirail, 2006, p. 45- 59. 
HALBWACHS. M. La mémoire collective. Paris: Puf, 1950.

LATOUR, B. Reensamblar lo social: una introducción a la teoría del actor-red. Buenos Aires: Manantial, 2008.

LAW, J. Notas sobre a teoria do ator-rede: ordenamento, estratégia e heterogeneidade. 200_? Disponível em: <www.necso.ufrj.br/Trads/Notas\%sobre\%"“20teoria\%20AtorRede.htm>. Acesso em: 22 de maio de 2009.

LE GOFF, J. História e memória. 4. ed. Tradução de Irene Ferreira et al.Campinas: UNICAMP, 1996.

MARX, K.; ENGELS, F. A ideologia alemã: teses sobre Feuerbach. São Paulo: Centauro, 2006.

MEYRIAT, J. Pour une compréhension plurisystemique du documento (par intencion). In: COURBIÈRE, C.; RÉGIMBEAU, G. Dimensions sociales du document. Toulouse: Press Univer. du Mirail, 2006, p. 11-28.

NIETZSCHE, F. Da utilidade e dos inconvenientes da história para a vida. In: Considerações intempestivas. Lisboa: Proença/São Paulo: Martins Fontes, 1976.

PACHECO, L. S. A informação enquanto artefato. Informare, Rio de Janeiro, v.1, n. 1, p. 20-24, jan./jun. 1995.

PAULA NETO, S. Compartilhamento de recursos de aprendizagem em pesquisa: estudo de consórcios acadêmicos de periódicos eletrônicos. 2005. Dissertação (Mestrado em Ciência da Informação) - PPGCI/PUCCAMP, Campinas, 2005.

RICOEUR, P. La mémoire, l'hoistoire, l’oubli. Paris: Seuil, 2000.

Tempo e narrativa. Campinas: Papirus, 1997. Tomo III.

SEARLO, B. Tempo passado: cultura da memória e guinada subjetiva. São Paulo: Companhia das Letras; Belo Horizonte: UFMG, 2007.

SILVA, E. P.; FERNANDES, G. C.. A temporalidade como constituinte do documento de arquivo: problematizando relações entre os contextos de geração, de tratamento e de uso dos documentos. Morpheus, Rio de Janeiro, v. 9, n. 4, 2009. Disponível em: < http://www.unirio.br/morpheusonline/numero14-2009/>. Acesso em: 12 de março de 2011.

SILVA, H. R. "Rememoração"/ comemoração: as utilizações sociais da memória. Rev. Bras. de História, São Paulo, v. 22, p. 425-438, 2002. Disponível em: <www.scielo.br/pdf/rbh/v22n44/14006.pdf>. Acesso em: 18 jan. 2011.

SOUZA, J. C. C. E. Avaliação de linguagem de indexação aplicada à informação jornalística: estudo de caso. 2007. Dissertação (Mestrado em Ciência da Informação) IBICT/UFF, Niterói, 2007. 